\title{
An Unusual Formation of Median Nerve with Absence of Musculocutaneous Nerve
}

\author{
Gupta Shalini ${ }^{1 *}$, Mittal Anupama ${ }^{2}$, Gautam Prateek ${ }^{3}$, \\ ${ }^{*}$ ( Department of Anatomy, Mayo Institute of Medical Sciences, India) \\ 2 ( Department of Anatomy, Subharti Medical College, India) \\ 3 (Department of Anatomy, Saraswathi Medical College, India)
}

\begin{abstract}
The Musculocutaneous nerve arises from the lateral cord of the brachial plexus, passes inferiorly and laterally, and then pierces through the coracobrachialis.After supplying it descends between the biceps and the brachialis, giving branches to both the muscles and continues as the lateral cutaneous nerve of the forearm. Variations in the origin, course, branching pattern, termination and connections of the musculocutaneous nerve $(M C N)$ are not uncommon. Though its absence has been described previously but its real prevalence is unknown.

A case of absence of the musculocutaneous nerve was observed during the dissection of the left arm of a male cadaver. The medial root of median nerve was found to be bifurcated and the area of innervation was supplied by lateral root of median nerve. From this, three branches emerged: one to the coracobrachialis muscle, another to the biceps brachii muscle and the third to the brachialis muscle.

The knowledge of such Anatomical variations would be of value to the practicing

neurosurgeons, orthopaedic surgeons, anaesthetist and interventional radiologists, during surgical procedures, including brachial plexus block and in diagnostic clinical neurophysiology to avoid unexpected complication.
\end{abstract}

Keywords: Musculocutaneous nerve, Median nerve, Neuro-muscular anomalies.

\section{I . Introduction}

The musculocutaneous nerve arises from the lateral cord of the brachial plexus, opposite the lower border of the pectoralis major, its fibres being derived from C5, C6 and C7. It penetrates through coracobrachialis muscle and passes obliquely between the biceps brachii and the brachialis, to the lateral side of the arm. A little above the elbow it pierces the deep fascia lateral to the tendon of the biceps brachii and continue into the forearm as the lateral cutaneous nerve of the forearm and supplies the lateral margin of the skin of the forearm.

In its course through the arm it innervates the coracobrachialis, biceps brachii, and the greater part of the brachialis.

- The branch to the coracobrachialis is given off from the nerve close to its origin, and in some instances as a separate filament from the lateral cord of the plexus; it is derived from the seventh, cervical nerve.

- The branches to the biceps brachii and brachialis are given off after the musculocutaneous has pierced the coracobrachialis; that supplying the brachialis gives a filament to the elbow-joint.

- The nerve also sends a small branch to the bone, which enters the nutrient foramen with the accompanying artery.

After branching to form the musculocutaneous nerve, the lateral cord continues as a lateral root of the median nerve, joining the medial root at the level of the distal margin of the pectoralis minor muscle in front of the axillary artery. The median nerve does not have any muscular branches in the arm.

In this case during routine dissection we observed the absence of the musculocutaneous nerve from the lateral cord of brachial plexus with innervation of the anterior compartment of the muscles of the arm by the lateral root of the median nerve. Such variations may be present clinically or may be observed during surgery. Since there is a high incidence of variations, they are important for neurologist, orthopaedicians and traumatologist and will assist clinicians and the surgeons by pointing out anatomical anomalies associated with the origin of musculocutaneous nerve and variations in the origin of muscular branches to the anterior compartment muscles of the upper arm. So, a detailed study was done to observe the variations of the musculocutaneous nerve .

\section{Materials And Methods}

A male cadaver age 55 years embalmed with $33 \%$ formalin was carefully dissected specially the pectoral region, the axilla and the arm. The cords and the branches of the cords in the infraclavicular part of the brachial plexus were cleared. The absence of the musculocutaneous nerve was noted along with lateral root of 
median nerve supplying anterior compartment muscles .Appropriate photographs were taken as per documentation.

\section{Case Report}

During routine dissection of the axilla and arm regions of 55-year-old male Indian cadaver in the Department of Anatomy Mayo Medical College, it is observed that in the infraclavicular part the lateral cord of the brachial plexus did not give of musculocutaneous nerve. Instead the lateral root of median nerve pierced the coracobrachialis muscle and supplies it[FIG 1]. The branch from lateral root of median nerve which supplied brachialis continued as lateral cutaneous nerve of forearm.

Other branch, which was higher in origin, supplied the biceps brachii and originated about $4 \mathrm{~cm}$ below where the lateral root pierced coracobrachialis. After branching, the lateral root crossed downwards and medially to form the median nerve .Formation of median nerve is taking place almost in the lower third of arm. One peculiar finding was that the medial root of median nerve was covered by an musculo-aponeurotic tunnel which may cause compression of the root and present neurological symptoms.[FIG 2]. In the right axilla and arm the course and origin of musculocutaneous nerve was as usual. No other anatomical variations were found in the brachial plexus or the nerves of the left arm, forearm and hand. Nor were there any in the subclavian, axillary or brachial arteries or their branches.

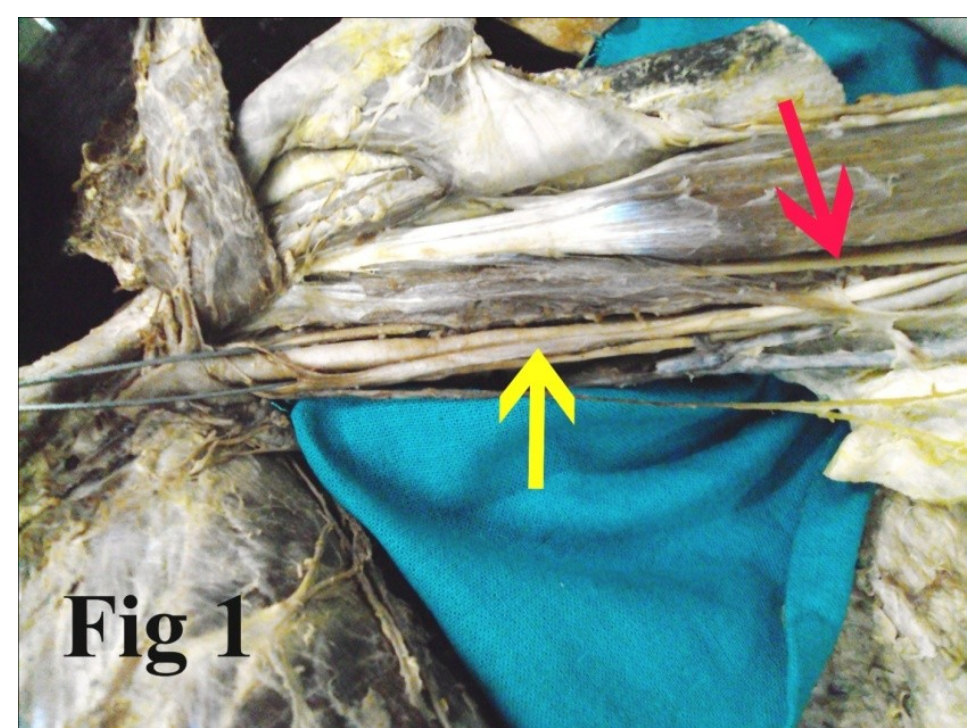

Fig:-1; Yellow arrow showing medial root of median nerve and Red arrow showing lateral root of median nerve.

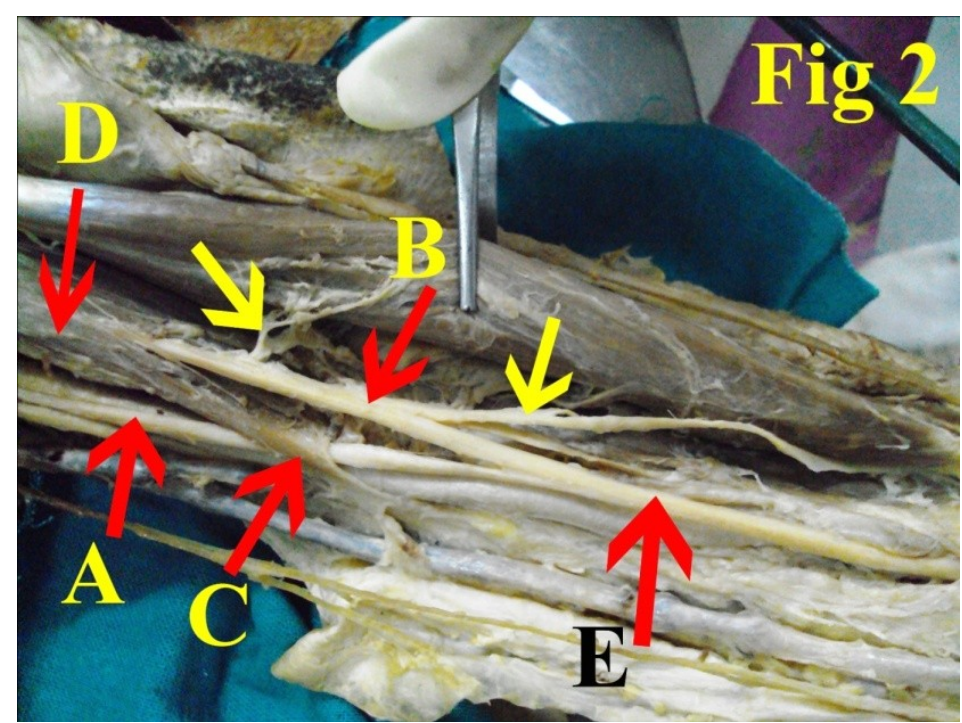

Fig 2:-. A-Medial root of median nerve; B-Lateral root of median nerve; C-Musculo-aponeurotic tunnel; D-

Coracobrachialis; E-Formation of Median nerve; Yellow arrow shows muscular branches 


\section{Discussion}

Contrary to what might be imagined, anatomical variations involving the brachial plexus are not very unusual: they are found in around $13 \%$ of dissections on cadavers.

Its absence has been described previously, but its real prevalence is unknown.[1,]

There is little data in the literature on the prevalence of absence of the musculocutaneous nerve, very few have reported about it.[2,3].Its prevalence ranging from 1.7 to $15 \%[4,5$,$] .$

Nakatani et al $(1997)^{6}$, Le Minor $(1992)^{7}$ have reported either unilateral or bilateral absence of MCN. . Beheiry dissected 60 arms and noted absence of the nerve in only one of them (1.7\%).[5]. Prasada Rao and Chaudhary[1] did not find this nerve in $8 \%$ of the 24 arms they dissected. Absence of the musculocutaneous nerve does not lead to paralysis of the flexor musculature of the elbow and hypoesthesia of the lateral surface of the forearm, since the motor and sensitive fibres can arise from other nerves. The most common situation is that its fibres originate from the median nerve or, less frequently, from the lateral root of the median nerve or from the lateral fasciculus of the brachial plexus[7,8,9,10,11]

Mohamad bilal delvi $(2011)^{12}$ advocated caution in performing the axillary block (a type of Regional aesthetic Block) acknowledging the existence of variations in the course of MCN.

\section{Conclusion}

The anatomical variation described here has practical implications, since injury to the median nerve in the axilla or arm would, in this case, have caused unexpected paresis or paralysis of the flexor musculature of the elbow and hypoesthesia of the lateral surface of the forearm, in addition to the classical signs that are already well known. A comprehensive knowledge of the existence of such an atypical presentation and course of MCN would be of immense value to the anaesthetist during the performance of axillary blocks, for plastic surgeons during flap dissections, for neuro-surgeons in diagnosing and treating post traumatic peripheral neuropathies and reconstructive nerve grafting following brachial plexus injuries and coracoids process grafting and shoulder arthroplasty procedures for orthopaedic surgeons.

\section{Reference}

[1] Prasada Rao PV, Chaudhary SC. Absence of musculocutaneous nerve: two case reports. Clin Anat. 2001;14(1):31-5.

[2] Bergman RA, Thompson SA, Afifi AK, Saadeh FA: Compendium of the human anatomic variation. Urban and Schwarzenberg, Baltimore.1988; 138-43.

[3] Williams PL, Bannister LH, Berry MM, Collins P, Dyson M, Dussek JE et al. Nervous system. In: Gray's Anatomy. 38th edition. Churchill Livingston, Edinburgh, London I995: 1267-72.

[4] Arora L, Dhingra R (2005) Absence of musculocutaneous nerve and accessory head of biceps brachii: a case report. Indian J Plast Surg 38:144-146

[5] Beheiry EE (2004) Anatomical variations of the median nerve distribution and communication in the arm. Folia Morphol 63:313318

[6] Nakatani T. et al. Three cases of the musculocutaneous nerve not perforating the coracobrachialis muscle. Acta Anat Nippon, 1997; 72: 191-194

[7] Le Minor JM. A rare variation of the median and the musculocutaneous nerve in man. Arch Anat Embryol, 1990; 73: 33-42.

[8] Gümüsburun E; Adigüzel E. A variation of the brachial plexus characterized by the absence of the musculocutaneous nerve: a case report. Surg Radiol Anat. 2000; 22(1):63-5.

[9] Song WC, Jung HS, Kim HJ, Shin C, Lee BY, Koh KS. A variation of the musculocutaneous nerve absent. Yonsei Med J. 2003;44(6):1110-3.

[ 10] Tatar I, Brohi R, Sen F, Tonak A, Celik H. Innervation of the coracobrachialis muscle by a branch from the lateral root of the median nerve. Folia Morphol (Warsz). 2004;63(4):503-6.

[11] Aydin ME, Kale A, Edizer M, Kopuz C, Demir MT, Corumlu U. Absence of the musculocutaneous nerve together with unusual innervation of the median nerve. Folia Morphol (Warsz). 2006;65(3):228-31.

[12] Mohamed Bilal Delvi (2011). Ultrasound - guided peripheral and truncal blocks in paediatric patients. Saudi Journal of Anaesthesia 5(2) 208-216. 